\title{
A study on knowledge, attitude and practices regarding antenatal care among pregnant women attending antenatal clinic at a tertiary care hospital
}

\author{
Rajvir Kaur*, Poonam Taneja, Isha Nandal
}

Department of Obstetrics and Gynecology, SGT Medical College and Research Institute, Budhera, Gurugram, Haryana, India

Received: 30 January 2021

Accepted: 04 March 2021

*Correspondence:

Dr. Rajvir Kaur,

E-mail: rajvir3kaur7@gmail.com

Copyright: () the author(s), publisher and licensee Medip Academy. This is an open-access article distributed under the terms of the Creative Commons Attribution Non-Commercial License, which permits unrestricted non-commercial use, distribution, and reproduction in any medium, provided the original work is properly cited.

\section{ABSTRACT}

Background: The maternal health level of Indian women was noticed to be inferior as compared to other developed countries. Antenatal care is the clinical assessment of both mother and foetus, during the period of pregnancy. Safe motherhood by providing good antenatal care (ANC) is very crucial to reduce maternal mortality ratio and infant mortality rate and to achieve millennium development goals. The objectives of this study aimed to assess the level of knowledge, attitude, and practice on ANC among pregnant women attending the antenatal clinic and their association with several sociodemographic factors.

Methods: A cross-sectional study was undertaken among 200 pregnant women in their 3rd trimester attending the OPD in a Tertiary Care Hospital of Gurugram, Haryana. Predesigned questionnaire was used for collecting data by interview after obtaining informed consent.

Results: This study revealed that about 55\% women had adequate knowledge regarding ANC. It was found that almost all the variables such as age, parity, level of education, occupation and type of family had a significant association with awareness about ANC. $90 \%$ women were having a positive attitude towards ANC. Around 70\%, women were practicing this adequately.

Conclusions: These results can be used to design a Health Intervention Program targeting to upgrade the maternal health practices and ultimately progress the health status of the women.

Keywords: Antenatal, Knowledge, Attitude, Practice, Third trimester

\section{INTRODUCTION}

Safe Motherhood Initiatives, a worldwide effort was launched by the World Health Organization in 1987 which intended to lessen the number of deaths associated with pregnancy and childbirth. ${ }^{1}$ Apt antenatal care (ANC) is one of the pillars of this scheme.

Antenatal care is the clinical evaluation of both mother and foetus, during the period of pregnancy. It is a main entry point for gravid women to receive multiple range of health facilities such as prevention, detection and treatment of sexually transmitted infections, nutritional maintenance, prevention or treatment of anaemia. ${ }^{2}$

Antenatal care is considered as a strong pillar of obstetrical facilities and it is the way to determine and deal with maternal and fetal complications. The pregnant women are classified as either normal or high risk at the very first antenatal check-up visit and with the aid of a special booking checklist. ${ }^{3}$

WHO recommends four antenatal visits in low-risk pregnancies, like the first visit in the first trimester, preferably before 12 weeks, but no later than 16 weeks, 
and the second, third, and fourth visits at 24-28, 32, and 36 weeks, respectively. ${ }^{4}$

One of the eight-millennium development goals (MDGs) is improving maternal health. Since 1990, maternal deaths worldwide have declined by $47 \%$. Although the health status of women has upgraded over the years due to determined efforts of Government of India, it is still not at par with the worldwide benchmark which is too high.

Early entry to ANC is vital for early detection and treatment of pregnancy-related adverse outcomes as it imparts information to expecting mothers that enable them to identify possible warning signs of complications during pregnancy as well as plans to adhere to prescribed treatments and referrals. It has been shown that around $80 \%$ of maternal mortality could be averted if the affected mother had a timely access to the essential maternity and fundamental health-care services. ${ }^{5}$

Health knowledge is an important component to empower women to be cognizant of their health status and the importance of appropriate ANC. This study was conducted to assess the level of knowledge, attitude, and practice related to antenatal care among the pregnant women and to evaluate the awareness about their own health during pregnancy.

\section{METHODS}

A cross-sectional study was carried out to assess the knowledge, attitude, and practices regarding ANC among pregnant women attending the antenatal OPD in SGT Medical College and Hospital, Gurugram in October to November 2020. A total of 200 pregnant females in the 3rd trimester, attending OPD were included in this study after taking informed verbal consent.

All the eligible participants were interviewed using a structured questionnaire which included sociodemographic profile and question's pertaining to knowledge, attitude and practice regarding ANC. Predesigned, pretested questionnaire was used. [Annexure 1].

Knowledge was assessed about ANC visits, tetanus immunization, investigations, nutritional factors, danger signs of pregnancy. Each parameter was awarded 1 mark for the correct response and 0 mark for wrong response. Thus, total marks for questions related to knowledge were 21. Those who scored $70 \%$ and above were considered as having adequate knowledge, and those who scored below $70 \%$ were considered inadequate knowledge.

Variables to assess attitude were an opinion on the place of delivery, ANC registration, visits, investigations, dietary changes, and iron and folic acid (IFA) intake and its regularity in the intake. Each attitude questionnaire was scaled using 5-point Likert scale. Total score for questions related to attitude were carrying 30 marks. Those who scored $70 \%$ and above were considered as having a good attitude toward ANC.

Questions were asked to assess the practices with regards to ANC visit, dietary changes made during pregnancy, IFA tablets taken and tetanus immunization during pregnancy. Each parameter was awarded 1 mark for good practice and 0 marks if the practice was not found appropriate. Thus, total marks for questions related to practices were 10 . Practice on attending number of visits carried 2 marks $(<3$ visits $=0,3-5$ visits $=1$ and $>5$ visits $=2$ ). Practice of duration of POG at 1 st antenatal visit scored 5 marks (Between 1st and 2nd month= 5, 2-3rd month $=4,3-4$ th month $=2$, Others $=1$ ). Those who scored $70 \%$ and above were considered as practicing adequately and those who scored below $70 \%$ were considered inadequate practices with regard to ANC.

Demographic characteristics namely age, parity, type of family, education and occupation were selected for studying association with knowledge and practices regarding ANC. For the ease of study, age is categorized into two categories namely age $\leq 21$ years and $>21$ years. Type of family was divided into two categories namely joint family and nuclear family.

\section{RESULTS}

In our study, the age range of study subjects ranges from 19 to 38 years with mean age of 25.15 years. 112 women were primigravida and 88 were multigravida. In this study the participants who married at $\leq 21$ years of age were 144 and 56 women married at $>21$ years. $6 \%$ postgraduate, $23 \%$ graduate, $45 \%$ intermediate, $10 \%$ until middle school, $9 \%$ until primary school. Only $7 \%$ women have not attended any formal schooling. About $88 \%$ women were unemployed and were working as housewives, and only $12 \%$ were working.

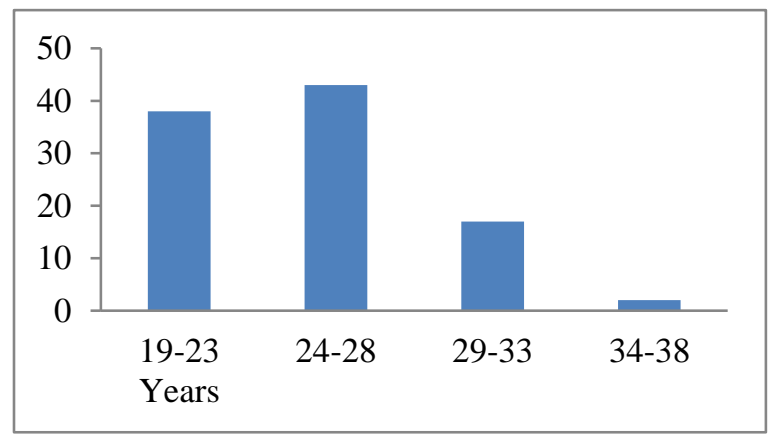

Figure 1: Age (in years).

$50 \%$ take joint decision with family while for $40 \%$ participants decision makers are in-laws and for $10 \%$ participants decision is taken by husbands only. $73 \%$ respondent belonged to joint family followed by $27 \%$ nuclear. 


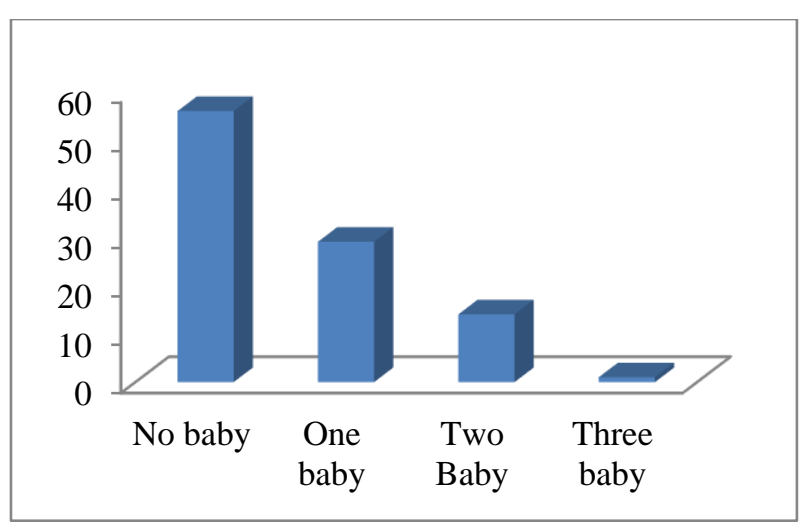

Figure 2: Parity.

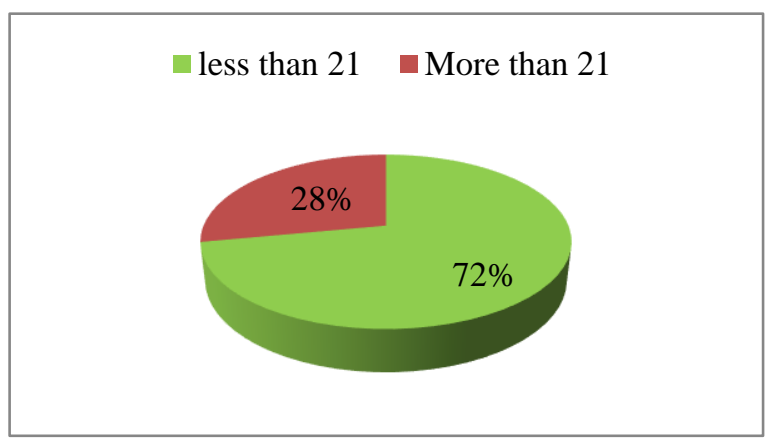

Figure 3: Age at marriage.

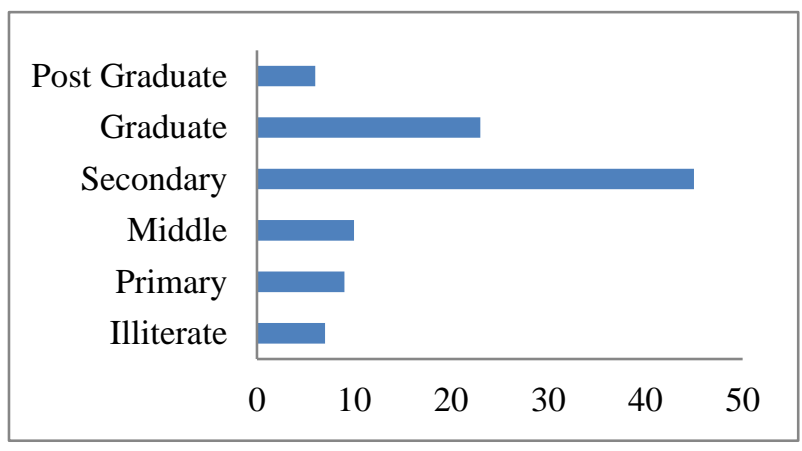

Figure 4: Qualification.

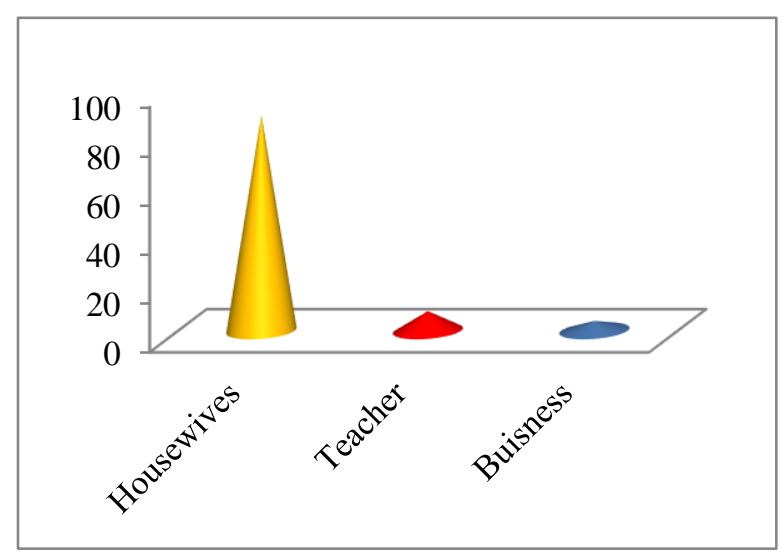

Figure 5: Occupation.
Antenatal women who belonged to age group of 24-28 years scored maximum mean knowledge, attitude and practice score followed by 29-31 years. It is clearly evident that knowledge is not significantly associated with increasing parity $(\mathrm{P}=0.317)$.

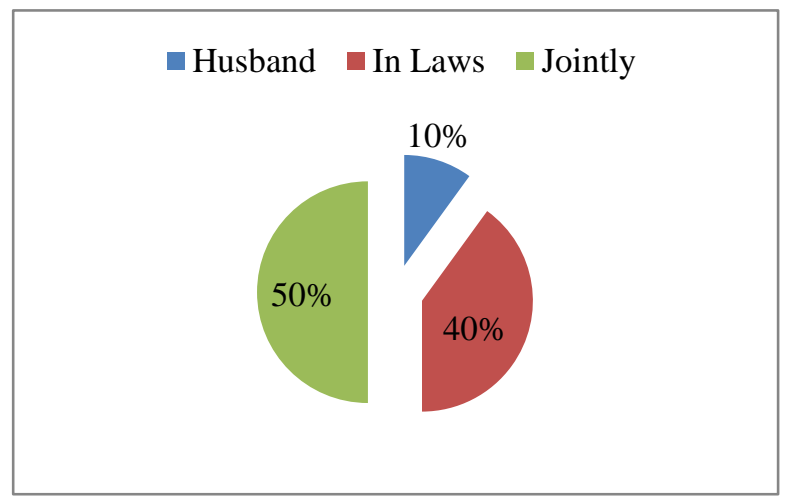

Figure 6: Decision maker.

Age of marriage $>21$ years showed significant results for knowledge and attitude compared to age of marriage $<21$ years. Age at 1 st child $\geq 24$ years showed significant results for knowledge and attitude compared to age at 1st child $<24$ years. But age of marriage and age at 1 st child has no effect on practice of antenatal care.

Knowledge about ANC care was associated more closely with those women who were more educated $(\mathrm{P}=0.001)$. Although the adequate knowledge women were distributed among both employed and unemployed women, but it was more associated with employed women. It means that working women were more knowledgeable than unemployed women $(\mathrm{P}=0.004)$.

Illiterate participants had least knowledge, positive attitude and practice followed by middle, primary, secondary and graduation and post-graduation.

$55 \%$ had adequate knowledge about overall ANC care. $90 \%$ women scored more than $70 \%$ marks meaning they have a positive attitude towards ANC care. $70 \%$ study subjects followed adequate ANC practices. [Table 1]. [Table 2] and [Table 3] summarize the association of knowledge, attitude and practices regarding antenatal care with sociodemographic factors.

Significant relation was found between decision maker and overall knowledge about ANC $(\mathrm{P}=0.001)$. Similar trends were noted between decision maker and positive attitude regarding $\mathrm{ANC}$.

There was no significant relation found between type of family and overall Knowledge about ANC. $(\mathrm{P}=0.699)$. It was found that women who had previous delivery in hospital had more knowledge $(\mathrm{p}=0.007)$ and positive attitude $(\mathrm{p}=0.001)$ as compared to home delivery but no effect seen on practice. 
Table 1: Association between selected demographic factors with overall ANC knowledge.

\begin{tabular}{|c|c|c|c|c|c|c|c|}
\hline & & Inadequate & Adequate & Total & df & $\mathbf{X} 2$ & p-value \\
\hline \multirow{4}{*}{ Age (Years) } & 19-23 Years & 44 & 32 & 76 & \multirow{4}{*}{3} & \multirow{4}{*}{5.29} & \multirow{4}{*}{0.151} \\
\hline & $24-28$ & 28 & 58 & 86 & & & \\
\hline & $29-33$ & 16 & 18 & 34 & & & \\
\hline & $34-38$ & 2 & 2 & 4 & & & \\
\hline \multirow{4}{*}{ Parity } & No baby & 54 & 58 & 112 & \multirow{4}{*}{3} & \multirow{4}{*}{3.53} & \multirow{4}{*}{0.317} \\
\hline & One baby & 20 & 38 & 58 & & & \\
\hline & Two babies & 14 & 14 & 28 & & & \\
\hline & Three babies & 2 & 0 & 2 & & & \\
\hline \multirow{2}{*}{ Religion } & Hindu & 80 & 108 & 188 & \multirow{2}{*}{1} & \multirow{2}{*}{3.79} & \multirow{2}{*}{0.052} \\
\hline & Muslim & 10 & 2 & 12 & & & \\
\hline \multirow{2}{*}{ Age at marriage } & less than 21 & 84 & 60 & 144 & \multirow{2}{*}{1} & \multirow{2}{*}{18.47} & \multirow{2}{*}{0.001} \\
\hline & More than 21 & 6 & 50 & 56 & & & \\
\hline \multirow{2}{*}{ Age at 1st child } & $19-23 y r s$ & 32 & 26 & 58 & \multirow{2}{*}{1} & \multirow{2}{*}{6.22} & \multirow{2}{*}{0.013} \\
\hline & $24-28 \mathrm{yrs}$ & 6 & 28 & 34 & & & \\
\hline \multirow{6}{*}{ Qualification } & Illiterate & 14 & 0 & 14 & \multirow{6}{*}{5} & \multirow{6}{*}{20.59} & \multirow{6}{*}{0.001} \\
\hline & Primary & 16 & 2 & 18 & & & \\
\hline & Middle & 16 & 4 & 20 & & & \\
\hline & Secondary & 44 & 46 & 90 & & & \\
\hline & Graduate & 0 & 46 & 46 & & & \\
\hline & Post-graduate & 0 & 12 & 12 & & & \\
\hline \multirow{3}{*}{ Occupation } & Housewives & 90 & 86 & 176 & \multirow{3}{*}{2} & \multirow{3}{*}{11.16} & \multirow{3}{*}{0.004} \\
\hline & Teacher & 0 & 16 & 16 & & & \\
\hline & Business & 0 & 8 & 8 & & & \\
\hline \multirow{3}{*}{ Decision maker } & Husband & 20 & 0 & 20 & \multirow{3}{*}{2} & & \\
\hline & In Laws & 38 & 42 & 80 & & 15.74 & 0.001 \\
\hline & Jointly & 32 & 68 & 100 & & & \\
\hline Tynes of fomily & Nuclear & 26 & 28 & 54 & 1 & 015 & 0609 \\
\hline Types of tamily & Joint & 64 & 82 & 146 & 1 & 0.15 & 0.699 \\
\hline Deliverv & At home & 10 & 0 & 10 & 1 & 742 & 0007 \\
\hline Deinery & Hospital & 28 & 50 & 78 & 1 & 1.42 & 0.007 \\
\hline
\end{tabular}

Table 2: Association between selected demographic factors and attitude.

\begin{tabular}{|c|c|c|c|c|c|c|c|}
\hline & & Inadequate & Adequate & Total & df & $\mathbf{X} 2$ & p-value \\
\hline \multirow{4}{*}{ Age (years) } & 19-23 Years & 12 & 64 & 76 & \multirow{4}{*}{3} & \multirow{4}{*}{5.78} & \multirow{4}{*}{0.123} \\
\hline & $24-28$ & 4 & 82 & 86 & & & \\
\hline & $29-33$ & 2 & 32 & 34 & & & \\
\hline & $34-38$ & 2 & 2 & 4 & & & \\
\hline \multirow{4}{*}{ Parity } & No baby & 12 & 100 & 112 & \multirow{4}{*}{3} & \multirow{4}{*}{0.74} & \multirow{4}{*}{0.864} \\
\hline & One baby & 4 & 54 & 58 & & & \\
\hline & Two babies & 4 & 24 & 28 & & & \\
\hline & Three babies & 0 & 2 & 2 & & & \\
\hline \multirow[t]{2}{*}{ Religion } & Hindu & 18 & 170 & 188 & \multirow[b]{2}{*}{1} & \multirow{2}{*}{0.32} & \multirow{2}{*}{0.572} \\
\hline & Muslim & 2 & 10 & 12 & & & \\
\hline \multirow{2}{*}{$\begin{array}{l}\text { Age at } \\
\text { marriage }\end{array}$} & less than 21 & 20 & 124 & 144 & \multirow{2}{*}{1} & \multirow{2}{*}{4.32} & \multirow{2}{*}{0.038} \\
\hline & More than 21 & 0 & 56 & 56 & & & \\
\hline \multirow{2}{*}{$\begin{array}{l}\text { Age at 1st } \\
\text { child }\end{array}$} & $19-23$ & 10 & 50 & 60 & \multirow[b]{2}{*}{1} & \multirow{2}{*}{2.99} & \multirow{2}{*}{0.084} \\
\hline & $24-28$ & 0 & 32 & 32 & & & \\
\hline \multirow{5}{*}{ Qualification } & Illiterate & 8 & 6 & 14 & \multirow{5}{*}{5} & \multirow{5}{*}{33.05} & \multirow{5}{*}{0.001} \\
\hline & Primary & 0 & 18 & 18 & & & \\
\hline & Middle & 8 & 12 & 20 & & & \\
\hline & Secondary & 4 & 86 & 90 & & & \\
\hline & Graduate & 0 & 44 & 44 & & & \\
\hline
\end{tabular}




\begin{tabular}{|c|c|c|c|c|c|c|c|}
\hline & & Inadequate & Adequate & Total & df & $\mathrm{X} 2$ & p-value \\
\hline & Post-graduate & 0 & 14 & 14 & & & \\
\hline \multirow{3}{*}{ Occupation } & Housewives & 20 & 156 & 176 & \multirow{3}{*}{2} & \multirow{3}{*}{1.52} & \multirow{3}{*}{0.123} \\
\hline & Teacher & 0 & 16 & 16 & & & \\
\hline & Business & 0 & 8 & 8 & & & \\
\hline \multirow{3}{*}{$\begin{array}{l}\text { Decision } \\
\text { maker }\end{array}$} & Husband & 6 & 14 & 20 & \multirow{3}{*}{2} & & \multirow{3}{*}{0.085} \\
\hline & In Laws & 6 & 74 & 80 & & \multirow{2}{*}{4.94} & \\
\hline & Jointly & 8 & 92 & 100 & & & \\
\hline \multirow{2}{*}{$\begin{array}{l}\text { Types of } \\
\text { family }\end{array}$} & Nuclear & 10 & 136 & 146 & \multirow{2}{*}{1} & \multirow{2}{*}{2.98} & \multirow{2}{*}{0.084} \\
\hline & Joint & 10 & 44 & 54 & & & \\
\hline \multirow{2}{*}{ Delivery } & At home & 8 & 2 & 10 & \multirow{2}{*}{1} & \multirow{2}{*}{34.32} & \multirow{2}{*}{0.001} \\
\hline & Hospital & 0 & 78 & 78 & & & \\
\hline
\end{tabular}

Table 3: Association between selected demographic factors with overall ANC practices.

\begin{tabular}{|c|c|c|c|c|c|c|c|}
\hline & & Inadequate & Adequate & Total & df & $\mathbf{X} 2$ & p-value \\
\hline \multirow{4}{*}{ Age (in years) } & 19-23 Years & 28 & 48 & 76 & \multirow{4}{*}{3} & \multirow{4}{*}{2.62} & \multirow{4}{*}{0.454} \\
\hline & $24-28$ & 18 & 68 & 86 & & & \\
\hline & $29-33$ & 12 & 22 & 34 & & & \\
\hline & $34-38$ & 2 & 2 & 4 & & & \\
\hline \multirow{4}{*}{ Parity } & No baby & 26 & 86 & 112 & \multirow{4}{*}{3} & \multirow{4}{*}{3.63} & \multirow{4}{*}{0.304} \\
\hline & One baby & 22 & 36 & 58 & & & \\
\hline & Two babies & 12 & 16 & 28 & & & \\
\hline & Three babies & 0 & 2 & 2 & & & \\
\hline \multirow{2}{*}{ Religion } & Hindu & 58 & 130 & 188 & \multirow{2}{*}{1} & \multirow{2}{*}{0.54} & \multirow{2}{*}{0.462} \\
\hline & Muslim & 2 & 10 & 12 & & & \\
\hline \multirow{2}{*}{$\begin{array}{l}\text { Age at marriage } \\
\text { (in years) }\end{array}$} & less than 21 & 48 & 96 & 144 & \multirow{2}{*}{1} & \multirow{2}{*}{1.36} & \multirow{2}{*}{0.244} \\
\hline & More than 21 & 12 & 44 & 56 & & & \\
\hline \multirow{2}{*}{$\begin{array}{l}\text { Age at 1st child } \\
\text { (in years) }\end{array}$} & $19-23$ & 24 & 32 & 56 & \multirow{2}{*}{1} & \multirow{2}{*}{0.13} & \multirow{2}{*}{0.718} \\
\hline & $24-28$ & 10 & 22 & 32 & & & \\
\hline \multirow{6}{*}{ Qualification } & Illiterate & 2 & 12 & 14 & \multirow{6}{*}{5} & \multirow{6}{*}{3.10} & \multirow{6}{*}{0.685} \\
\hline & Primary & 8 & 10 & 18 & & & \\
\hline & Middle & 6 & 14 & 20 & & & \\
\hline & Secondary & 24 & 66 & 90 & & & \\
\hline & Graduate & 14 & 32 & 46 & & & \\
\hline & Post Grad. & 6 & 6 & 12 & & & \\
\hline \multirow{3}{*}{ Occupation } & Housewives & 54 & 122 & 176 & \multirow{3}{*}{2} & \multirow{3}{*}{0.16} & \multirow{3}{*}{0.923} \\
\hline & Teacher & 4 & 12 & 16 & & & \\
\hline & Business & 2 & 6 & 8 & & & \\
\hline \multirow{3}{*}{ Decision maker } & Husband & 4 & 16 & 20 & \multirow{3}{*}{2} & & \\
\hline & In Laws & 26 & 54 & 80 & & 0.6 & 0.741 \\
\hline & In Jointly & 30 & 70 & 100 & & & \\
\hline & Nuclear & 10 & 44 & 54 & & 232 & 8120 \\
\hline Types of tamily & Joint & 50 & 96 & 146 & 1 & 2.32 & 0.128 \\
\hline & At home & 6 & 4 & 10 & 1 & 109 & 0.297 \\
\hline Delivery & Hospital & 28 & 50 & 78 & 1 & & \\
\hline
\end{tabular}

\section{DISCUSSION}

Our findings revealed that 55 out of 100 antenatal women obtained good knowledge score regarding birth preparedness. Another study conducted in Belagavi, also found that awareness of the concept of birth preparedness was $77.1 \%$ among the women. ${ }^{6}$
Findings of present study indicate that 90 percent of antenatal women had positive attitude regarding birth preparedness, these are consistent with the study conducted in Padukka which concluded that that 75 percent pregnant women had favourable attitude regarding birth preparedness and complication readiness. ${ }^{7}$

In our study, mean age for respondents was 24 years with age range from 19 to 38 years. Our study showed 
statistically significant association between age and knowledge about ANC but not with overall ANC practices. A study done by Sanjel et al., 2011 in Tamang also shows a significant association between age and knowledge. ${ }^{8}$

Our findings regarding parity revealed that knowledge, attitude and practice regarding birth preparedness was not higher in primipara as compared to multipara. Opposite to these are the findings of other study conducted to assess status of birth preparedness and complication readiness in Madhya Pradesh which stated that birth preparedness/complication readiness were significantly higher in primi-para as compared to multipara. ${ }^{9}$

Nuclear family has more knowledge regarding birth preparedness as compared to joint and extended family

Agarwal et al. in their study in 2007 found that ANC received was significantly lower among illiterate women. ${ }^{10}$ This finding is similar with our finding in which women who were more educated were better aware about almost all the factors of ANC. However, women with lower education $(<10$ th) were performing better in term of visits and women with higher education (>10th) were doing better practice. Overall educated women were practicing in a better way than non-educated women.

In this study $55 \%$ had adequate knowledge about overall ANC care. $90 \%$ women have a positive attitude towards ANC care. $70 \%$ study subjects followed adequate ANC practices. Kawungezi et al. 2015 study showed that women who had received antenatal care, $54.5 \%$ did not have sufficient knowledge of the service, only $45.5 \%$ had good knowledge. ${ }^{11}$ Attitude towards antenatal care is becoming positive due to better outcomes in health of the baby and the mother.

The practice of home delivery is still common act as added risk if they ever want to conceive again. About half of the women did not know the complications that might arise among pregnant women.

In this study $11 \%$ of the women reported having experience of home delivery in their previous pregnancies.

\section{CONCLUSION}

The still higher proportion of $(45 \%)$ of pregnant women has inadequate knowledge, and about one-third of study participant have poorly practice ANC care. Their knowledge on certain aspects of ANC were still poor especially regarding the importance of early antenatal check-up, health screening and complications related to diabetes and hypertension in pregnancy.

These results can be used to design a Health Intervention Program targeting to upgrade the maternal health practices and ultimately progress the health status of the women.

Hence, it is better if local health offices arrange community-based education and empowering women by escalating educational opportunities. Antenatal care clinics should give due importance to planning for birth and its complications and should provide information and education to all pregnant women.

\section{Funding: No funding sources}

Conflict of interest: None declared

Ethical approval: The study was approved by the Institutional Ethics Committee

\section{REFERENCES}

1. World Bank. Safe Motherhood - A Review. The Safe Motherhood Initiatives, 1987-2005 World Bank Report. New York: Family Care International; 2007

2. Berhe KK, Welearegay HG, Abera GB, Kahsay HB, Kahsay AB Assessment of antenatal care utilization and its associated factors among 15 to 49 years of age women in Ayder Kebelle, Mekelle City 2012/2013; a cross sectional study. Open Journal of Advanced Drug Delivery. 2014;2(1):62-75

3. Bande MI, Chutiyami M, Shehu U, Garba MS, Effects of Socio Demographic and Institutional Factors on Utilization of Antenatal Care Services among Pregnant Women in Damaturu, Yobe State, Nigeria. International Journal of tropical disease \& Health. 2018;29(2):1-9.

4. World Health Organization. World Health Statistics. $2017 . \quad$ Available at: www.who.int/gho/publications/world_health_statisti cs/2014/en/.

5. Al hazmi JM, Habib HM, Sebeih SH, Khan MI, Elmaghrabi SA, et al. Awareness of Antenatal Care Importance among Saudi Pregnant. Journal of Gynecology and Women's Health. 2017;4(4):1-15.

6. Padaguggari I, Shivaswamy MS, Chougule, S. A cross-sectional study on knowledge and practices regarding birth preparedness and complication readiness among pregnant women attending antenatal clinic at KLE'S Dr. Prabhakar Kore Hospital and Medical Research Center, Belagavi. Indian J Health Sci Biomedic Res (KLEU). 2018;11.

7. Rodrigo $\mathrm{CH}$, Kumarapeli V. Birth prepared-ness, complication readiness and associated factors among pregnant women attending antenatal clinics at medical officer of health (MOH) area Padukka. BMJ open. 2015;5(1).

8. Sanjel S, Ghimire RH, Pun K. Antenatal care practices in Tamang community of hilly area in central Nepal. Kathmandu Univ Med J (KUMJ). 2011;9:57-61.

9. Kushwah SS, Dubey D, Singh G, Shivdasani JP, Adhish V, Nandan D. Status of birth preparedness \& complication readiness in Rewa District of Madhya Pradesh. Indian J Public Health 2009;53(3):128-32. 
10. Agarwal P, Singh MM, Garg S. Maternal health-care utilization among women in an urban slum in Delhi. Indian J Community Med. 2007;32:203-5.

11. Kawungezi PC, AkiiBua D, Aleni C, Chitayi M, Niwaha A, Kazibwe A, et al. Attendance and utilization of antenatal care (ANC) services: multi- center study in upcountry areas of Uganda. Open journal of preventive medicine. 2015;5(3):132.

Cite this article as: Kaur R, Taneja P, Nandal I. A study on knowledge, attitude and practices regarding antenatal care among pregnant women attending antenatal clinic at a tertiary care hospital. Int $\mathbf{J}$ Reprod Contracept Obstet Gynecol 2021;10:1621-8. 
ANNEXURE 1

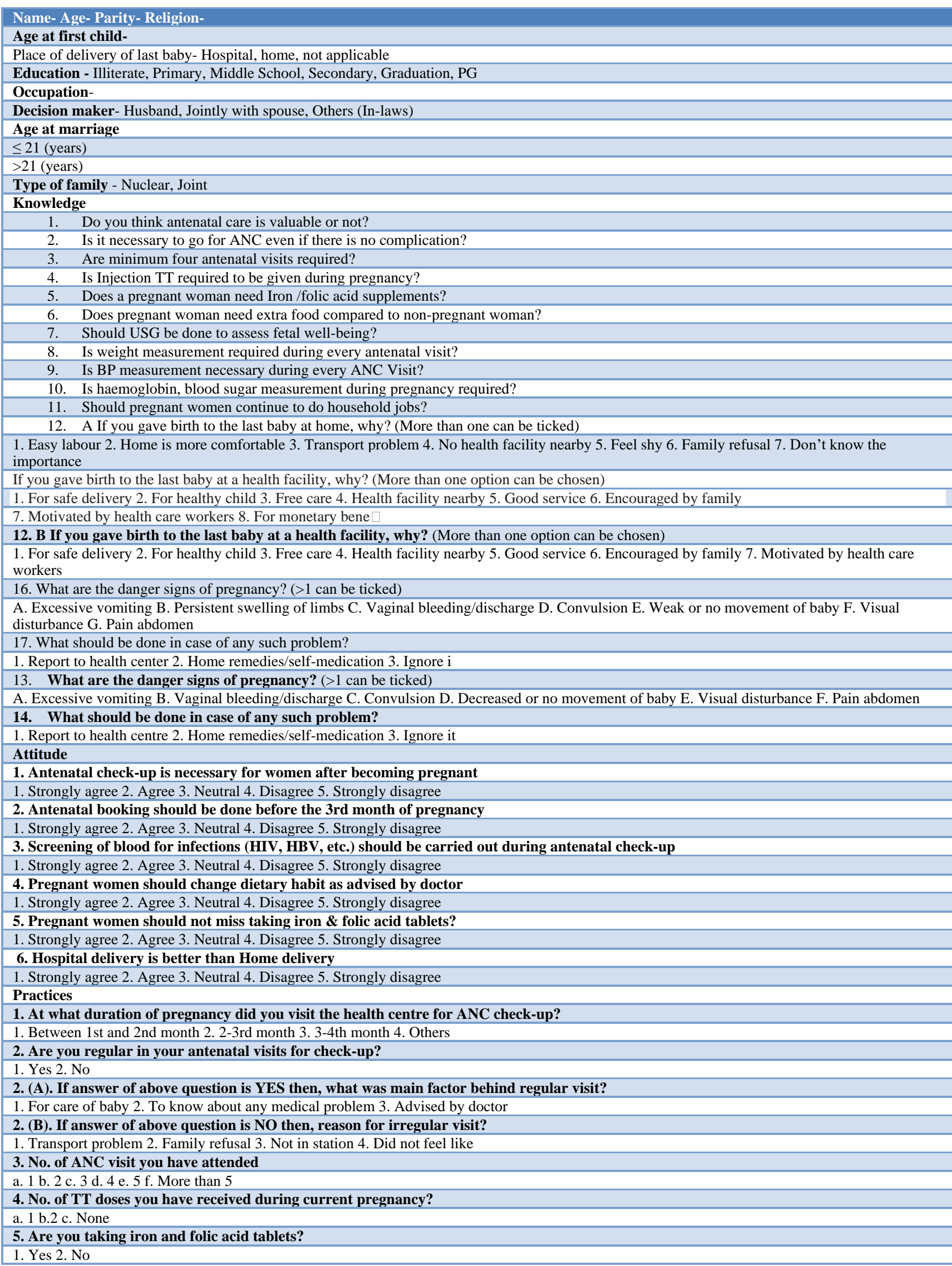

